\title{
A mini project: monitoring and assessment for water quality of study area, gombak river
}

\begin{abstract}
The proposal for this project was submitted to the National River Care Fund, Malaysia on Sept-Oct 2016 by a group of students from the UCSI University Aquatic Science Student Association (AQSA). The location of the project was selected as a continuation of the community services carried out by a previous batch of students. The seven month project was used to measure water quality parameters for the Gombak river at the Batu 12 village location. Samples were collected each month from February 2017 until August 2017. Based on the water quality testing which indicated that the water is not contaminated or polluted, it was decided that an aquaponic system would be constructed instead of the hydroponic system mentioned in the proposal because the water quality is good enough for both vegetables and fish to grow and the community can benefit from this system. A suitable area for setting the systems up was identified and site preparation activities were commenced immediately. The water in the aquaponic system was quarantined for a month before the fish were transfered to it from the laboratory. Local communities are guided and advised to monitor the systems and seed germination will be carried out by them regularly. The students from UCSI University were able to convert their knowledge learned in classes into a practical application during the project timeline.
\end{abstract}

Volume 3 Issue 2 - 2018

\author{
Regina LZL, ${ }^{1,2}$ Teo SS, ${ }^{1,2}$ Tennat A, ${ }^{3}$ Lim LH ${ }^{1,2}$ \\ 'Aquatic Science Programme, Department of Applied Sciences, \\ UCSI University, Malaysia \\ ${ }^{2}$ Aquatic Science Student Association, Department of Applied \\ Sciences, UCSI University, Malaysia \\ ${ }^{3}$ Stella Maris International School, Malaysia
}

Correspondence: Lim LH, Department of Applied Sciences, UCSI University, No.I Jalan Menara Gading, UCSI Heights, 56000 Cheras, Kuala Lumpur,W. P. Kuala Lumpur, Malaysia, Tel: 603-910-188-80, Email limlh@ucsiuniversity.edu.my

Received: December 18,2017 | Published: March 14, 2018

\section{Introduction}

Overpopulation has become one of the most pressing environmental concerns. This increase in world population has led to more pressure affecting some of the core environmental aspects of our existence. Aspects including energy security, climate change, air pollution, water quality and land-use change. The expansion of human activities pressures the environmental services that are supplied by nature. The environmental impacts derived from global warming, acid rain, air pollution, waste disposal, water pollution and many more affect every ecosystem and organism. Environmental issues have become an important concern and are an important part of international relations. Society, as a whole, is becoming more aware of the environmental impacts that we, humans, are creating. Advances in information technology and growing access to the internet means that greater numbers of people have access to more information than at any other time in human history. This knowledge availability can be one of the drivers that can help us to overcome the environmental issues that we have created. Non-governmental organizations (NGO), with cooperation from state governments, have come together to derive strategies related to the protection of Mother Earth for future generations. One of the methods to find out the causal agents or problems that might be affecting an ecosystem is by monitoring and assessment. The principles of environmental monitoring and assessment is designing the monitoring systems using different parameters, and then use that monitoring information in assessing the effects of natural resources management and pollution risks. Environmental monitoring is necessary to estimate the present status of the ecosystem and thus to establish a baseline for further monitoring. This baseline can then be used to estimate trends and identify the problem in the environment and test for compliance with standards. This type of approach is especially appropriate for aquatic systems. In order to identify and estimate the possible types and amounts of contaminants entering the water-bodies a panel of potential contaminants first needs to be established. Statistical analysis is commonly used to ensure all the measurements taken at regular intervals over a substantial period of time have a useful degree of reliability. ${ }^{1}$

Natural resources support economic activities in many ways. In Malaysia, individuals and organizations are needed for cooperative action to support effective and sustainable natural resource use. However, as mentioned above, human population size has increased tremendously and this means demand for resources and goods has also grown. This increase in demand and pressure on environmental services can be clearly seen as an impact on numerous water-bodies around the country around the country. Increasingly, the rivers and sea have been damaged by the disposing of all kinds of waste into these systems. Due to such irresponsible behavior, the ponds, lakes, stream, rivers, estuaries and oceans are becoming polluted in Malaysia (Malaysia Environmental Quality Report 2009). Water quality is the evidence of the health of an ecosystem. It sustains the ecological processes for organism populations, wetlands, birdlife and vegetation. At various sites along the Gombak River (Sungai Gombak), the major problems contributing to pollution are sewage discharge, chemical discharge, wastewater treatment plant discharge, industrial discharge and rapid urbanization. ${ }^{2,3}$ The Malaysia government has implemented a number of campaigns to collect solids wastes from the Gombak River and as a result the impact of solid waste has been reduced. For example, River of Life (ROF) was tasked by the Department of Irrigation and Drain (DID) to monitor, coordinate and ensure the river is well managed. Unfortunately, the most difficult types of waste to remove are dissolved salts such as nitrates, phosphates, ammonia and other nutrients, and toxic metal ions.

Another impact is suspended particulates, particularly from runoff from tin mining and palm oil plantations. ${ }^{4,5}$ This impacts the turbidity 
of the water, which has an impact on aquatic life and may cause issues with spawning, feeding and fowling of gill slits. ${ }^{6,7}$ These issues affect a significant area of Malaysia. However, it impacts those groups of people designated as "Orang Asli" more severely than most others. The Orang Asli are the ethnic natives of Malaysia and still rely heavily on traditional methods of food gathering and for fresh water. These traditional methods are greatly dependent on rivers. ${ }^{8}$ One such catchment area and river is the Gombak river system.

An option for supplementing the traditional methods of food harvest from rivers is the use of aquaponics. Particularly gravity flow systems that will not require electricity and can use indigenous species. This sort of system can supplement, or even temporarily replace, traditional harvest when the environment is placed under stress from human impacts. Aquaponics is an approach that utilizes both aquaculture for raring fish and hydroponics for growing plants. Each part of the system supplements the other and nitrogenous waste, which can be very harmful to the environment, is reduced or removed. ${ }^{9-12}$ Therefore, there is a need to propose a plan in order to monitor and manage the status of the Gombak River by measuring the water quality and analyzing the parameters of $\mathrm{pH}$, Biochemical Oxygen Demand (BOD), Chemical Oxygen Demand (COD), Dissolved Oxygen (DO), turbidity, ammonia content, phosphate content, heavy metals and total suspended solids. In addition the use of a naturally occurring species of fish, Tilapia, was proposed as a bioindicator species. This species was supplemented with another fish, Puyu, and a local vegetable species called Kangkong.

\section{Site description}

The study area of this proposal is the Gombak River. The Gombak River is a slow-flowing river that flows through the Selangor and Kuala Lumpur districts of peninsula Malaysia. The Gombak River is located mainly in Gombak District, Selangor and the downstream zone is located in the capital, Kuala Lumpur. This river has confluences with other streams such as Batu River, Untut River and Klang River It is a tributary area in the upper part of the Klang river basin. Around $60 \%$ of the catchment is steep mountains with heights of up to $1220 \mathrm{~m}$. The river drainage system is elongated to the south-west of Kuala Lumpur. The Sungai Pusu, Sungai Keroh, and Sungai Salak feed into the Gombak River. The drainage basin is $22.2 \mathrm{~km}$ with an average width of $5.5 \mathrm{~km}$ and an area of 123.3 square $\mathrm{km}$. The Gombak River joins with the Batu River and then meets with the Klang River in the center of Kuala Lumpur city. The watershed areas are enclosed by hilly mountains. It can be divided into three main sections; upper zone, middle zone and lower zone. The upper zone is an undisturbed forest reserve. The middle and lower zones flow directly into the urban area of Kuala Lumpur and show worsening water quality. ${ }^{13}$ The Gombak River is selected in this study because there are many Orang Asli settlements located along its length. These indigenous peoples depend on the river for many of their daily activities. The location of the Gombak River is shown in Figure 1.

\section{Sources of pollution}

There are a number of activities carried out within the river basin that impact the environment. These include deforestation, agricultural activities, and industrial and urban development. Rapid human population increase and uncontrolled human activities have led to pollution of the river. Previously, the water quality of the Gombak River was categorized as falling within Class II and Class III (Malaysian Water Quality standards) and this indicates the river water is polluted and needs treatment. ${ }^{14}$ If action is not taken in this situation, the quality of water will deteriorate to Class IV which indicates the water is seriously contaminated. Thus, the objective of this study was to monitor and assess the water quality of the Gombak River to find out if it is suitable for human consumption, especially for Orang Asli settlements.

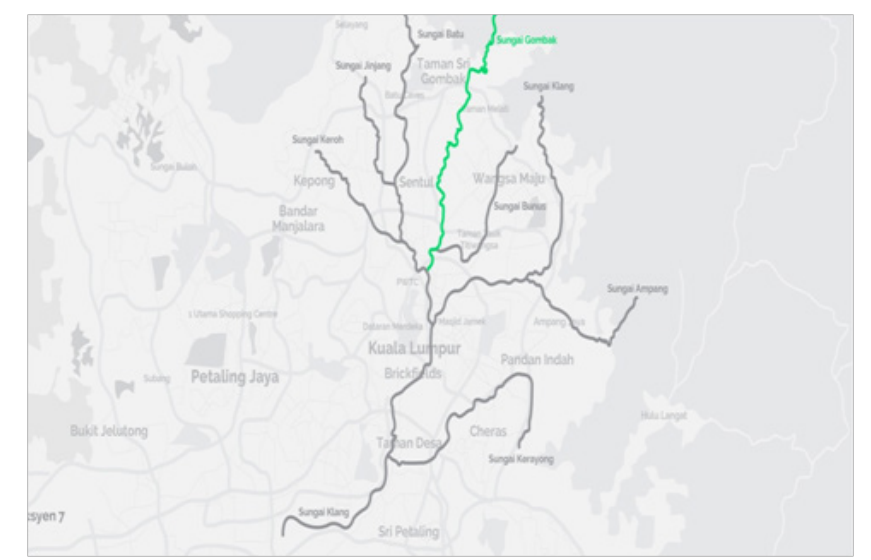

Figure 1 The location of the Gombak River.

\section{Methodology}

Water quality monitoring is defined as water sampling and analysis. The monitoring program will evaluate the physical, chemical and biological parameters. Each parameter, including $\mathrm{pH}$, turbidity, ammonia content, phosphate content, and total suspended solid was monitored and analyzed from February 2017 to August 2017. The sampling locations are at, or near to, Batu 12 Village $(3.289 ; 101.731)$. Water sampling is carried out at 6 different points along the river. There are 2 different points upstream of the Batu 12 village, 2 different points within the Batu 12 village and 2 different points downstream of the Gombak River watershed. These points were selected as this river is the main source for various activities in Selangor and the status of the water quality can be determined from these points. Water samples collected from different sites are analyzed and tested with standard testing kits. The water samples collected will be tested for water quality by measuring physio-chemical parameters including $\mathrm{pH}$, turbidity, ammonia content, phosphate content and potassium content. Determination of water quality using physio-chemical parameters will be tested in situ. In addition, a trial aquaponics system was also utilized to initially monitor water quality and also serve as a test bed for food production. Fish and vegetables that are locally available were selected for the initial monitoring and trial period. The fish species selected are Tilapia and Puyu. The vegetable is Kangkong. The water is delivered from the river to the aquaponics system by gravity flow and then returns to the river by gravity flow. The Kangkong grows on a sponge substrate in trays suspened above plastic tanks and water drip feeds through to the tank. The Tilapia and Puyu are in the black plastic tanks. See Figure 1 below for a view of the aquaponics setup (Figure 2).

\section{Results}

All the parameters are tested both in situ and ex situ and the data are recorded in Table 1. The tests results from the runoff water from the aquaponics system are included in Table 1 as a combined total as the system is directly linked to the river. Turbidity is a measurement of water clarity by measuring the amount of light scattered and absorbed by a water sample rather than transmitted in straight lines through the sample. Turbidity of the river from Feb 2017 to Aug 2017 is averaged as $3.5 \mathrm{NTU}$. 
Table I The water quality of the Gombak River from Feb 2017 to Aug 2017 in the area of the Batu I2 village

\begin{tabular}{|c|c|c|c|c|c|c|c|}
\hline & I7-Feb & I7-Mar & I7-Apr & I7-May & I7-Jun & I7-Jul & I7-Aug \\
\hline $\mathrm{pH}$ & $7.17+0.11$ & $6.37+0.05$ & $6.64+0.05$ & $6.70+0.00$ & $6.74+0.04$ & $6.71+0.02$ & $6.64+0.03$ \\
\hline $\mathrm{NO}^{3-\mathrm{N}}(\mathrm{mg} / \mathrm{L})$ & $8.33+0.51$ & $|0.66+0.5|$ & $11.83+2.13$ & $11.25+0.50$ & $12.00+0.0$ & $16+1.41$ & $|4.75+0.5|$ \\
\hline $\mathrm{Na}^{+}(\mathrm{ppm})$ & $3+0.0$ & $3+0.0$ & $3+0.0$ & $3+0.0$ & $3+0.0$ & $3+0.0$ & $3+0.0$ \\
\hline $\mathrm{K}^{+}(\mathrm{ppm})$ & $2+0.0$ & $2+0.0$ & $2+0.0$ & $2+0.0$ & $2+0.0$ & $2+0.0$ & $2+0.0$ \\
\hline $\mathrm{Ca}^{2+}(\mathrm{ppm}$ & $1+0.0$ & $2+0.0$ & $2+0.0$ & $2.25+0.50$ & $2.25+0.50$ & $2.25+0.50$ & $2+0.0$ \\
\hline Copper (mg/L) & 0 & 0 & 0 & 0 & 0 & 0 & 0 \\
\hline
\end{tabular}

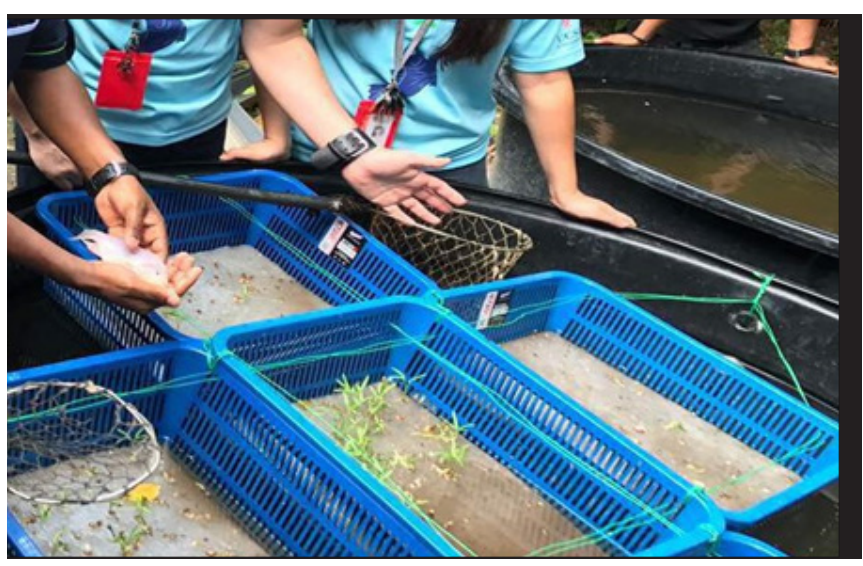

Figure 2 Aquaponics system

\section{Discussion}

Based on the water analysis from Feb 2017 to August 2017, the river water does not have any readings that indicate it exceeds the Malaysian guidelines for water quality. Nitrates were found to be present in the water in low amounts, $11.70 \pm 2.58 \mathrm{mg} / \mathrm{L}$. Excess nitrates $(>50 \mathrm{mg} / \mathrm{L})$ in water is a sign of poor water quality. In an anaerobic environment (sludge/soil at the bottom), denitrification can be used to convert nitrate back to nitrite and from there, to nitrogen gas. This removes the total nitrogen in the aquatic system. Levels exceeding $50 \mathrm{mg} / \mathrm{L}(\mathrm{ppm})$ indicate an unhealthy condition for aquatic organisms. In a water body containing aquatic organisms, carbon dioxide is produced during respiration. Excess carbon dioxide can be removed from the water by the photosynthetic processes of aquatic plants, thus increasing the $\mathrm{pH}$ levels. Carbon dioxide plays a role in lowering $\mathrm{pH}$. $\mathrm{pH}$ is used to categorize the sample as acid, neutral or alkaline (basic). The $\mathrm{pH}$ levels of most natural waters are between $\mathrm{pH} 5.0$ to $\mathrm{pH} 8.5$ Fresh rainwater may be around $\mathrm{pH} 5.5$ to 6.0. It is undesirable to have $\mathrm{pH}$ levels too high in a water body as free ammonia increases with rising $\mathrm{pH}$. The $\mathrm{pH}$ levels of the water sampled from our practical site were on average $6.72 \pm 0.25$. It is neutral and within the range of acceptable water $\mathrm{pH}$ levels. Copper is toxic to aquatic organisms. It is sometimes used to kill unwanted algae, fungi and molluscs. Copper is moderately soluble in water and binds easily to sediments and organic matter. Fish gills may become frayed and lose their ability to regulate salt transport when exposed to copper. The copper levels found at the sampling sites were on average $0 \mathrm{mg} / \mathrm{L}$. This is a good sign as it would be detrimental to the health of the aquatic organisms living in the water as well as the humans living in the area.

Also included in the chemical monitoring is the discharge from the aquaponics systems. As the nitrate and $\mathrm{pH}$ measurements indicate, the aquaponics system was able to remove, or neutralise, and possible nitrogenous wastes that the fish will have generated and the system does not contribute any contaminants into the environment. While the measurement of physico-chemical parameters is a good start, longterm water quality can also be measured using bio-indicators which may give a better indication of the sometimes-complex relations of all the components in the water. Bio-indicators are naturally occurring organisms that can function as parameters to assess the health of the environment. Bio-indicators are living organisms including plants, animals, planktons and microbes that give an idea of the natural ecosystem's health. They are used to detect changes or trends of current status of ecosystem, monitor for the presence of pollutants and the effects on the ecosystem and monitor the progress of environmental action on the pollution. Aquatic microorganisms and fish communities are used in this research as they have sensitive characteristics to wideranging of chemicals exposed and can readily interpret biological effects of the contamination. ${ }^{15}$ In this case the bio-indicators are the organisms utilised in the aquaponics system. According to the Orang Asli at Batu 12 village, they mainly obtain Tilapia from the river (Personal communication). Fish communities respond significantly to all kinds of environment changes. Their sensitivity to the health of water quality serves as a good indicator to monitor environmental degradation. Both Tilapia (25 pcs) and Puyu ( 8 pcs) are able to grow in the aquaponic tanks for months, until achieving adult maximal growth and subsequently being harvested. Kangkong seeds are able to germinate after 3 days and continue growing in the aquaponic system. The successfull growth of these three organisms indicates that the water quality is of sufficiently good quality and does not contain any observable harmfull substances. Microorganisms are involved in biodegradation of sewage that may be introduced into a river and the sewerage, or other organic waste, contains a high amount of biodegradable organic matter. Microorganisms can be a good bioindicator because they utilize a lot of oxygen and this will directly affect the dissolved oxygen in the water-body. The sharp decline in dissolved oxygen will causes mortality to the aquatic organisms. In addition, high nutrient levels, in particular nitrogen and phosphate, will also encourage the growth of plankton and may lead to an algal bloom. Algal blooms causes deterioration of the water quality and fish mortality. Some algal blooms are also extremely toxic to other living organisms. ${ }^{16-20}$

\section{Conclusion}

The initial water testing indicated that the water was of sufficiently good quality to be able to initiate an aquaponics programme. Testing of the response of two fish species to the river water provided further data as to good water quality. The aquaponics system can now run according to need. Further long-term monitoring of water quality will be needed and it is suggested that bio-indicators be included in this programme. 


\section{Acknowledgement}

Firstly, we would like to thank Yayasan Hasanah for funding the project and National River Care Fund for implementing this project. Furthermore, we wish to thanks all AQSA members and UCSI University for the support throughout the projects.

\section{Conflict of interest}

The author decline there is no conflict of interest.

\section{References}

1. Bruns DA, Wiersma GB. Conceptual Basis of Environmental Monitoring Systems: A Geospatial Perspective. In 'Environmental monitoring. Boca Raton, FL [etc.]' (Ed Wiersma GB), 2004;631-647.

2. Ismail Zubaidah, Rahizah Sulaiman, Ramlee Karim. Evaluating trends of water quality index of selected kelang river tributaries. Environmental Engineering and Management Journal. 2014;13(1):61-72.

3. Bavani M. Rapid Urbanisation Leads to Pollution. The Star. 2016

4. Balamurugan G. Tin mining and sediment supply in peninsular Malaysia with special reference to the Kelang River Basin. Environmentalist. 1991;11(4):281-291.

5. Nurhidayu Siti, Muhammad Azhar, Mohammad Faizal Hakim Ahmad Shafuan. Long-term sediment pattern of the Selangor river basin, Malaysia impacted by land-use and climate changes. E-proceedings of the $36^{\text {th }}$ IAHR World Congres. 2015.

6. Chapman, Jacqueline M, Catherine L, et al. Clear as mud: A meta-analysis on the effects of sedimentation on freshwater fish and the effectiveness of sediment-control measures. Water Res. 2014;(56):190-202.

7. Giam Xingli, Renny K, Hadiaty, et al. Mitigating the impact of oil-palm monoculture on freshwater fishes in Southeast Asia. Conservation Biology. 2015; 29(5):1357-1367.

8. Chan WK. Orang Asli Issues: Environmental Blueprint First. Environmental and Climate Change Committee (ECCC), Bar
Council, Malaysia; 2016.

9. Blidariu F, Grozea A. Scientific Papers: Animal Science and Biotechnologies, 2011;44 (2).

10. Love DC, Fry JP, Genello L, et al. An International Survey of Aquaponics Practitioners. PLoS ONE. 2014;9(7):e102662.

11. Azad KN, Salam MA, Azad KN. Aquaponics in Bangladesh: current status and future prospects. Journal of Bioscience and Agriculture Research. 2016;07(02):669-677.

12. Yildiz HY, Robaina L, Pirhonen J, et al. Fish Welfare in Aquaponic Systems: Its Relation to Water Quality with an Emphasis on Feed and Faeces-A Review. Water. 2017;9(1):13.

13. Gorashi F, Abdullah A. Prediction of Water Quality Index Using Back Propagation Network Algorithm. Case Study: Gombak River. Journal of Engineering Science and Technology. 2012;7(4):447-461.

14. Mohd Sabri A, Mohd Sidek L, Mohamed Jaffar A. The relationship of river water quality parameters to river flow in Gombak River. International Conference on Global Sustainability and Chemical Engineering (ICGSE). 2014.

15. Chiarelli R, Roccheri M. Marine Invertebrates as Bioindicators of Heavy Metal Pollution. Open Journal of Metal. 2014;4(4): 93-106.

16. Deborah Chapman. Water Quality Assessments - A Guide to Use of Biota, Sediments and Water in Environmental Monitoring $-2^{\text {nd }}$ Edition, published on behalf of WHO by F \& FN Spon, 1996.

17. Whitton B. River ecology. 2nd ed. Berkeley, Calif: Blackwell Scientific Publications.1975;506-508.

18. WHO. Copper in Drinking Water. WHO Publications. 2004;3-5.

19. Yassen M, Md Jahi J. Investigation of Variations and Trends in TSP Concentrations in The Klang Valley Region, Malaysia. Malaysian Journal of Environmental Management. 2007;(8):57-68.

20. DA Bruns, GB Wiersma. Conceptual Basis of Environmental Monitoring Systems: A Geospatial Perspective, CRC press.2004. 